\title{
SOME COMMENTS ON PROFESSOR HART'S LEGAL SYSTEM-A REPLY TO PROFESSOR SUMMERS
}

\author{
PhILIP MULLOCK*
}

In a recent issue, this journal published an article by Professor Robert $S$. Summers reviewing and commenting critically upon a recent book by Professor H. L. A. Hart of Oxford entitled The Concept of Law. Among other things, Professor Summers criticized Professor Hart for stressing rules to the neglect of other elements of a legal system and for succumbing to reductionist tendencies in the analysis of such basic concepts as "courts" and "legislatures."

$\mathrm{D}$ ESPITE what some critics have said, the spate of reviews and comments it has provoked bears ample witness to the fact that there has been nothing quite like Professor H. L. A. Hart's The Concept of Law in the history of Anglo-American jurisprudence. Professor Summers' recent contribution to the dialogue ${ }^{1}$ indicates that he is both a faithful reviewer and a constructive critic. In this article I propose to do three things. First, I shall attempt to show that Professor Summers' criticism of Professor Hart's idea of a union of rules and his allegation of reductionism can be accommodated within the structure of Professor Hart's legal philosophy. Secondly, I shall consider the implications of Professor Summers' suggestion that Professor Hart's theory needs criteria, not only for recognizing the rules of a legal system but also for identifying the legal system itself. Finally, I shall discuss the connection, if any, between Professor Hart's concept of validity and his theory of a minimum natural law.

* J.D. 1958, University of Chicago; LL.M. 1959, University of Virginia. Member, Virginia Bar. Associate Professor of Law, Mercer University.

On the subject of modern mathematics, I have benefited from discussions with Pro. fessor Sherwood Ebey of the Mercer University faculty; he should not, however, be held responsible for anything $I$ have said.

${ }^{1}$ Summers, Professor H. L. A. Hart's Concept of Law, 1963 DUKE L.J. 629. 
II

A. Union of Rules

Professor Summers is not alone ${ }^{2}$ in his contention that Professor Hart claims too much for his union of primary and secondary rules. ${ }^{3}$ However, he goes further than most critics and adds that Professor Hart does not in fact use a combination of primary and secondary rules to elucidate any specific legal concept. At most, according to Professor Summers, he has succeeded merely in furnishing a criterion for differentiating the primitive and static society (primary rules only) from the modern dynamic state, i.e., the union of rules is relevant only to the elucidation of the general concept, the "legal system." 4 Such an assertion, however, fails to do justice to a major part of the point Professor Hart is making, because it does not take into account the basis upon which this part of Professor Hart's theory rests, and which, in my opinion, is to be found mainly in Kelsen.

It is impossible, says Kelsen, to understand the nature of law by looking at a rule in isolation. ${ }^{5}$ Many words cannot be understood except in reference to a system; for instance, to understand the words "baseball bat," we must refer to the system of baseball. Similarly, the legal quality of a legal rule is not to be perceived by gazing at it, for there cannot be a system of isolated rules. Kelsen also remarks that law regulates its own creation; ${ }^{6}$ in other words, it takes rules to make law. But what about the rules themselves? What does it mean to say that a rule exists? Is merely convergent, habitual behavior sufficient? If not, how do we distinguish such behavior (people go to the cinema on Saturday evening) from a social rule (men bare their heads on entering church)? Professor Hart explains the difference in this way. If one does not go to the cinema on Saturday evening, no one will care one way or the other. If, however, a man does not bare his head upon entering church, he will be met with hostile reactions. The distinguishing feature of a social rule, therefore, is that deviations from the rule will give rise to criticisms and reproofs which are considered

\footnotetext{
'See, e.g., Cohen, Book Review, 71 Mind 395 (1962).

Summers, supra note 1 , at 639 .

Id. at 639 n.16.

"Kelsen, General. Theory of Law and State 3 (1945 ed.) [hereinafter cited as KELSEN].

- Id. at 132.
} 
justified by those deviations. This fact finds its linguistic expression in certain normative words like should, ought, and must, which function as indicia of the presence of rules requiring certain conduct. ${ }^{\top}$ Legal rules in turn are a subspecies of social rules and fall into three broad categories: ${ }^{8}$ primary rules which impose duties, secondary rules which confer powers of adjudication and change, and rules of recognition which specify criteria for identifying the rules of the system. ${ }^{2}$ The union of these three types of rules, the fact that it takes rules to make law, is what, for Professor Hart, lies at the center of a legal system and illuminates many of the perplexing problems of jurisprudence. ${ }^{10}$

In commenting on Austin's theory that law is a system of orders backed by threats, Kelsen points out that when the gunman orders a bank clerk, "Hand over the money or I will shoot," he is not giving a binding order because bindingness implies that there is a rule which confers authority upon the person who gives the order.11 Therefore, even though the notion of orders backed by threats may in some cases convey the force of what we mean by law, it cannot be regarded as a definition of law. One significance, then, of Professor Hart's idea of a union of rules is that an important element in the analysis of concepts developed by theorists in talking about law is an implied reference to an unstated rule forming part of a system of rules. "Union" in this sense is certainly not a simple one-to-one combination in that we may, for example, add one primary rule to one secondary rule to get $X$, some legal concept.

Professor Summers asserts that in elucidating the concept of validity, Professor Hart uses the notion of a rule of recoguition rather than a union of rules. ${ }^{12}$ But what else could he use, and what more is necessary? When judge, attorney, and citizen state, "The rule that a will must be attested by two witnesses is valid in England," they are, according to Professor Hart, making internal statements, i.e., from the point of view of those living in a society in which the various transactions of life are conducted according to rules. They

\footnotetext{
' HART, The CONCEPT of LAw 54-56 (1961) [hereinafter cited as HART].

${ }^{8}$ Although Professor Hart uses the expression "secondary rules of recognition," HaRT 95, he does not now, if he ever really did, regard rules of recognition as secondáry rules. Rather than conferring powers upon anyone, these rules merely set out the tests for validity, i.e., the criteria for identifying what are to count as rules of the legal system.

o Hart 89-96.

${ }^{10} \mathrm{Id}$. at 96.

11 KELSEN 31-32.

12 Summers, supra note 1, at 639.
} 
all are making the statement intra system, as contrasted with an external statement made by an observer who, without accepting the rule himself, may assert that it is accepted in the society in question. Just as it is the internal (normative) aspect of rules as contrasted with merely convergent, habitual behavior which interests Professor Hart, so it is the internal need to identify which rules are to count as legal rules that is important to Professor Hart here. When judge, attorney, and citizen make the statement, "The rule that a will must be attested by two witnesses is valid in England," the function of the word "valid" in that statement is to make a reference to an unstated but accepted rule of recognition which specifies criteria for identifying the rules of the system. Insofar as Professor Hart's theory is concerned, this ends the matter. Analysis of a legal concept other than validity, however, will bring out that it presupposes a ruledetermined setting in which legal rules must be marshalled to support whatever is asserted in statements using such a concept. But when the concept in question is validity itself, any such addition would be superfluous because all that is needed, in Professor Hart's theory, is the notion of a rule of recognition; validity has syntactical meaning only. In discussing obligation, ${ }^{13}$ Professor Hart points out $^{14}$ that while Bentham's analysis of legal duty in terms of likelihood of suffering for doing or not doing $X$ no doubt reflects the force of the notion in certain contexts, it ignores the important point that the relation of pain to previous conduct must also be justified by rules. Legal duty is tied to the idea that if an obligatory act is not done, there will be a case under legal rules for applying sanctions. Hence any reference to legal duty presupposes a normative or ruledetermined setting and that there is a definable pattern of conduct, deviation from which should be held under legal rules to justify things being done to a person which otherwise would be resented and wrong under the system of rules. Bentham's omission of this setting is what, for Professor Hart, vitiates his theory. Again, in commenting on Hohfeld's four correlative senses of individual rights, Professor Hart suggests that most of the defects could be remedied by inserting as the central point the idea of an individual whose choice regarding whether to act or not to act is assisted rather

\footnotetext{
13 Professor Summers also states that Hart "uses only the notion of a "primary rule" to elucidate the concept of obligation." Ibid.

16 HART 81-83.
} 
than impeded by legal rules. ${ }^{15}$ The ascription of a legal right to $A$ is a statement of law, so that legal rules must be marshalled in support of it; and any reference to legal rules implies a reference also to an unstated rule for recognizing the rules of the system.

When Kelsen leads us up (down?) the hierarchy of norms, ${ }^{10}$ Professor Hart follows, ${ }^{17}$ stopping only when Kelsen takes the final step up (down?) to his basic norm. Both agree that it takes rules to make law. Professor Hart differs from Kelsen, however, in that he does not see why we must also postulate the validity of a basic norm which says that people ought to obey the historically first constitution. For Professor Hart, the historically first constitution is simply a matter of empirical fact - internal (intra system) acceptance - which is observable externally. ${ }^{18}$ In the modern society, rules of change and adjudication correct the static nature of a system containing primary rules only; rules of recognition enable us to identify the rules of the system. The word "law," when used in discourse about a modern society, implies a system having at least these three categories of rules which are necessary to keep it going in a dynamic fashion. When we develop concepts such as right and duty in talking about law, we cannot elucidate them properly without bringing into our analysis a reference to rules forming a part of a system of rules. This, I think, is the point of Professor Hart's union of rules, which to me seems to be a development of Kelsen's insight that law regulates its own creation. Just as Kelsen points out that the legal quality of a legal rule cannot be understood except by reference to a legal system, so for Professor Hart, the nature of a legal system cannot be perceived without an awareness that there can be no satisfactory analysis of the concepts developed by theorists in talking about law which does not recognize that in using those concepts, we are talking about some aspect of a system of rules.

\section{B. Reductionism}

Professor Summers asks the following questions, the implication being that Professor Hart is trying to do what in each case is questioned:

\footnotetext{
26 Hart, Definition and TheORY in JuRISPRUdENGE 17 (1953).

10 KiELSEN 115-16.

17 HarT 103-04.

1s Jil. at 106-07.
} 
1. Can laws be reduced to rules? ${ }^{19}$

2. Can rules be reduced to two classes?20

3. Can secondary rules be reduced to three types?21

4. Can the various criteria for identifying valid rules be reduced to a rule of recognition? ${ }^{22}$

5. Can courts be reduced to rules? ${ }^{23}$

6. Can legislatures be reduced to rules? ${ }^{24}$

Questions 2 and 3 are simply about classification, which surely is a philosophically harmless activity; the ability to see "the one in the many" should not be dismissed as reductionism. The answer to question 4 is that they cannot because they are not. As I shall indicate later, the criteria of identification need not be embodied in a rule at all; so far as I am aware, the Queen in Parliament has not enacted a rule to the effect that "In England only those rules enacted by the Queen in Parliament shall be recognized as legal rules." If such a rule has been enacted, then it is simply a legal rule. But this is not to say that the criterion of identification has been reduced to anything; it remains a criterion as long as it is accepted as such. Questions 5 and 6 possibly could involve reductionism, but to say that rules lie behind these institutions ${ }^{25}$ is not to reduce them to rules. It is difficult to see how Professor Summers can say that Professor Hart has shifted from a concept of law which required courts and a legislature to one which requires only rules ${ }^{26}$ merely because he now emphasizes a union of rules. His secondary rules of change still need a legislature, and the secondary rules of adjudication need both a legislature and courts. Professor Hart never suggests that he has reduced either the legislature to rules of change or the courts to rules of adjudication. Insofar as orders which have the force of law are concerned, Professor Hart can explain them simply by pointing out that they derive their legal force from rules. Otherwise, as Kelsen observed, the gunman's order would be entitled to the same respect as that of the judge. ${ }^{27}$

\footnotetext{
${ }^{10}$ Summers, supra note 1 , at 640 .

${ }^{20} \mathrm{Id}$. at 641.

${ }^{21}$ Id. at 642.

22 Ibid.

${ }^{28} \mathrm{Id}$. at 643 .

24 Ibid.

ss Ibid.

${ }^{20}$ Id. at $643-44$.

27 KELSEN 31-32.
} 
With respect to question $1, I$ have difficulty in understanding what Professor Summers is getting at, for in a footnote ${ }^{28}$ he adds that he does not mean to imply that Professor Hart says that laws can be reduced to rules. This question is linked by Professor Summers to the question, "Are principles rules?" Having cited Bishop Butler's well-known dictum, Professor Summers concludes, "Perhaps law is law, and not another thing."29 Perhaps, however, he should say that principles are principles but that they may be reflected in legal rules. Surely all we need say is that when we talk about "laws," we mean not only legal rules, but also all those things which derive their legal force from legal rules. Standards, principles, regulations, and orders may not be legal rules, but any legal force they have must be derived from legal rules.

\section{III}

Professor Summers seems to imply that in addition to criteria for determining the existence of the rules of a legal system, Professor Hart also needs to specify criteria for determining the existence of the legal system itself. ${ }^{30}$ Furthermore, his emphasis on the alleged reductionism ${ }^{31}$ indicates that Professor Summers regards Professor Hart's legal system as no more than the aggregate of legal rules. Although the latter would include rules of recognition embodying the system's criteria of identification, it would not include the criteria themselves. For example, assume the criterion of validity in England is to be "enacted by the Queen in Parliament." This is not a rule at all. A rule embodying this criterion might be: "In England only those rules enacted by the Queen in Parliament shall be recognized as legal rules." This would be a legal rule, a member of the class of legal rules; more precisely it would be a rule of recognition. Even though self-referring, its self-reference is syntactical and therefore harmless. The criterion itself, however, is not a rule at all; it is simply a criterion.

It must be remembered that we are dealing not with a class but with a system, a system made up at least of legal rules plus the criterion or criteria of identification. Let us use the symbols $L, R$, and

\footnotetext{
${ }^{20}$ Summers, supra note 1 , at 640 n.19.

${ }^{29} \mathrm{Id}$. at 641 . The dictum referred to in the text is "Everything is what it is, and not another thing."

${ }^{80} \mathrm{Id}$. at 647 .

81 Id. at $640-44$.
} 
$C$ to designate the legal system, the class of legal rules, and the criterion of identification respectively. If we now specify $C^{1}$ as a criterion of identification for $L$, we cannot accommodate $C^{1}$ within $L$, for it is neither $C$ nor a member of $R$. And if $R$ plus $C$ constitute $L$, then $L$ plus $C^{1}$ will make up another system $L^{1}$, ad infinitum. Of course, we do not have an infinity of legal systems. In fact there could be just one legal system in the world, even though not the legal system of a world state. On the other hand, we do have a multiplicity of legal systems. It is possible, as Kelsen argues, ${ }^{32}$ that all positive municipal legal systems are members of a positive international legal system, in which case the criterion for identifying positive municipal legal systems would be part of the international legal system also. Moreover, it might be argned that just as the notion of a legal rule cannot be grasped simply by looking at it, so the concept of a legal system cannot be understood except by reference to an international system of municipal legal systems. This may be Kelsen's viewpoint, but it overlooks the fact that we may want to and in fact do talk about a, the, our, and your legal system from different points of view, e.g., that of the lawyer and that of the political scientist. From the point of view of the lawyer, and therefore of the legal theorist, there is an internal need to talk about the or our legal system in a way which makes any reference to international law and a multiplicity of municipal legal systems quite irrelevant. The elucidation of the notions of right and duty, the explanation of what it means to say that I pay my taxes to the same state as did my grandfather, can be dealt with from the standpoint of legal theory within the framework of an analysis of $a$ legal system or $a$ state. In other words, analysis of the notion of a legal system and the concepts used in talking about law requires only that what is latent and implicit be made patent and explicit; the objective is clarification. We may, of course, differ in our analyses. However, if we are analyzing the jurisprudential notion of a legal system, we cannot bring into the analysis something which in fact is not contained in the analysandum because that would not be doing analysis, and Professor Hart is doing analysis. Therefore, if Professor Summers wants Professor Hart to specify criteria for the existence of a legal system, he is asking Professor Hart to do something other than analytical jurisprudence, for such criteria, as has

KELSEN 219-20, 363-88. 
been indicated, are not to be found within the concept "a legal system."

\section{IV}

The expression "legal system," like "right" and "duty," is not a ground floor term of law; rather, it is a concept developed by theorists in talking about law. Next to the word "universe," "system" is probably the broadest and loosest collective noun we use, and it is certainly less precise than those admittedly ambiguous terms, "class" and "set." The idea of a system has received its most sophisticated development in modern mathematics. Hence, since the relationship between Professor Hart's concept of validity and his theory of a minimum natural law must be sought within his concept of a legal system, it may be profitable to consider briefly the mathematician's idea of a system in the hope that useful analogies may be drawn. A modern mathematical system might be conceived of as being composed of classes within classes somewhat in the way a system of concentric circles contains circles within circles. ${ }^{33}$ The largest class, which enters into all other smaller classes, consists of all strings of symbols alphabet, punctuation and connectives-used in the system. Next, in descending order, is the class of well-formed formulae, i.e., those finite arrangements of symbols of which true or false can be predicated. This is followed by the class of theorems, those well-formed formulae which are deduced from the smallest class of the system, axioms, by the system's rules of inference and which can only be true. ${ }^{34}$ Gödel has shown ${ }^{35}$ that in any arithmetical system $P$, it is

\footnotetext{
st It is interesting to note that in his introduction to Austin's Province, Professor Hart states that "A legal system is a system of rules within rules." Hart, Introduction to Austin, The Province of Jurisprudence Determined at xii (libraxy of ideas ed. 1954).
}

8. $P$ might be represented as follows:

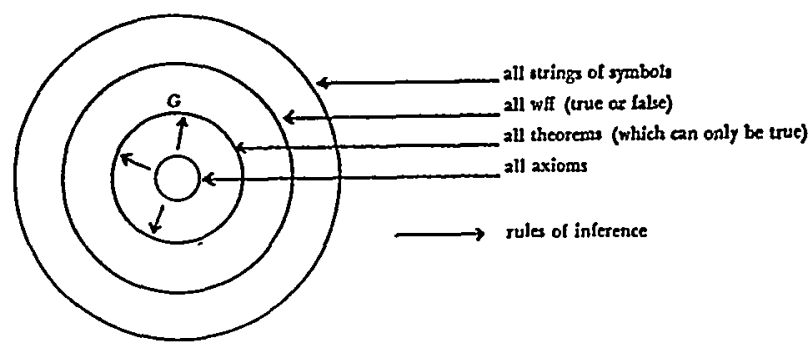

85 Göder, ON Formally Undectdable Propositions (Meltzer transl. 1962). See also W. \& M. KNeAle, The Development of Logic 712-24 (1962); NAgel \& NewMan, GödEL's Proof (1959). 
possible to construct a theorem $G$ (which is therefore a well-formed formula also) representing the metamathematical statement "The formula $G$ is not demonstrable" which cannot be deduced from the axioms of the system by its rules of inference, although as a theorem, $G$ must be true unless $P$ is self-contradictory. In effect the theorem says it is unprovable. If we try to remove this defect by adding $G$ as a new axiom, then $G$ becomes provable in the trivial sense that an axiom may be said to be provable because it follows from itself. But this will be so only within a new system $P^{1}$, and this in turn can be shown to be incomplete by the construction of a new Gödel theorem, say $G^{1}$, ad infinitum. Gödel's argument proves not only that $P$ is incomplete but also that it is incompletable. Although $G$ is, of course, self-referring, its self-reference is syntactical rather than semantical, and therefore it is harmless. It is neither faulty in the same way as the pseudo-statement "What I am saying is false" nor empty like the remark "What I am now saying is true." To say of theorem $G$ that it is well-formed means no more than that it is a meaningful arrangement of symbols; it is a form or pattern of which true or false can be predicated. The rules which enable us to say of $G$ both that it is a well-formed formula and a theorem are syntactical (as opposed to semantical) rules for the use of symbols, i.e., rules about their relation with each other as opposed to their relation to the world. There is nothing to prevent a statement from referring to its own pattern or form. If I say, "The statement I am now uttering contains nine words," this is not only free from paradox but it is also true. ${ }^{36}$

Let us now see what analogies can be drawn in legal theory by using $L$ as the legal analogue of $P$. Some natural law theorists think of a positive legal system $L$ as a system of rules logically deduced from self-evidently binding axioms. Legal rules in this case would be analogous to the theorems of $P$ rather than well-formed formulae, although as theorems they would, of course, be wellformed formulae. Both "Thou shalt kill" and "Thou shalt not kill" would be analogous to well-formed formulae, but only the latter would be both a well-formed formula and a theorem, i.e., a valid legal rule. It would also theoretically be possible to construct a rule $G$ which would be a legal rule and true and which yet

\footnotetext{
${ }^{86}$ Professor Alf Ross would disagree, I think, for he has stated that "A proposition cannot refer to itself." Ross, ON LAW AND Justice 81 (1958).
} 
could not be derived from the axioms of the system. What, if anything, the natural law theorist can or should do about this is not my present concern. The legal positivist, on the other hand, would deny any place in $L$ for the natural law theorist's axioms; legal rules would simply be analogous to well-formed formulae and could therefore be good or bad. Both "Thou shalt kill" and "Thou shalt not kill" would be valid legal rules analogous to well-formed formulae. This, however, could hardly satisfy Professor Hart because it ignores his minimum natural law which I shall now outline to see if analogies from modern mathematics can help in establishing its relation to his concept of validity.

Starting with survival as the end of human activity, the goal desired by all men, Professor Hart argnes ${ }^{37}$ to certain necessary social rules for the protection of persons, property, and promises which form the minimum content of natural law and which are common to law and morality. These are the rules of conduct which any social organization must contain if it is to be viable and which are necessitated by certain truisms about human beings and the world in which they live. In other words, assuming survival as an end and knowing what we know about human beings and their world, certain social rules become a matter of necessity. This does not mean, says Professor Hart, that the truisms, the natural facts of social life, are necessary causal conditions for the social rules in question; they are simply reasons why the rules are necessary. The rules, therefore, are not inductive generalizations established scientifically from sociological or psychological experiment and observation, although conceivably they might be so established. At the same time, Professor Hart avoids any charge of absolutism or dogmatism by insisting that survival, the natural fact of life, and the related truisms, the natural facts of social life, are contingently true only; conceivably things could be otherwise than they are. What emerges is thus a theory which purports to be empirical rather than metaphysical about a natural law which states contingent rather than absolute truths and which is established rationally rather than scientifically-a formidable achievement indeed.

It is obvious, I think, that Professor Hart's legal system $L$ must contain rules satisfying both his criterion of validity (e.g., enacted by the Queen in Parliament) and his minimum natural law. The

\footnotetext{
${ }^{87}$ HART 189-95.
} 
former may be said to be formal or syntactical, the latter material or semantical; and their relationship may be explained in the following manner. Let the symbol $A$ designate the class of all possibly valid legal rules, i.e., the class of all rules satisfying the criterion of identification $C^{1}$ (e.g., enacted by the Queen in Parliament), and let $L$ designate the subclass of all valid legal rules, namely those members of $A$ which also satisfy a second criterion $C^{2}$. But what is $C^{2}$ and how does a legal rule in class $A$ gain admittance into class $L$ ? The answer may be as follows. Let $x$ be any member of $A$, and let $a_{1}, a_{2}$, and $a_{3}$ be those valid legal rules constituting Professor Hart's minimum natural law which will therefore be members of $L$. Then for each $x$ in $A$, we can decide whether a certain relationship expressed in $x R a_{1}, x R a_{2}$, and $x R a_{3}$ holds, the relation $R$ being $C^{2}$; for an $x$ to be in $L$, we must be able to say of $x R a_{1}, x R a_{2}$, and $x R a_{3}$ that each is true. ${ }^{38}$ This relation $R$, and therefore $C^{2}$, must be the relation of being "not inconsistent with minimum natural law." The connection between $C^{1}$ and $C^{2}$, therefore, lies in the fact that for an $x$ to be in $L$, it must satisfy both $C^{1}$ and $C^{2}$; both must be satisfied if a rule is to be a valid rule of positive law. But what about $a_{1}, a_{2}$, and $a_{s}$ themselves? How do they get into $L$ in the first place? They are certainly not axioms, because nothing is deduced from them. Nor are they theorems, for they are not deduced from anything. Rather, they are in $L$ by "natural necessity," by which Professor Hart means that there are contingently true social facts which justify enacting rules with a certain material content. Once they have been enacted, we can enact any other legal rule not inconsistent with $a_{1}, a_{2}$, and $a_{3}$. Thus, to say of a legal rule that it is valid means that

$\mathbf{8 8}$

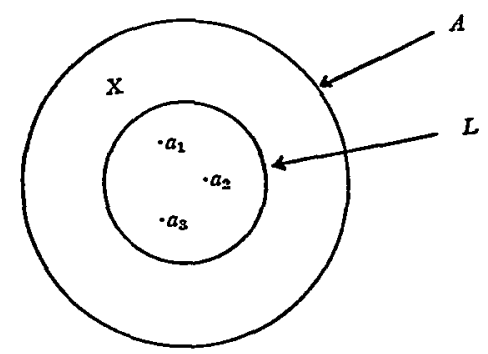

For $x$ to get from $A$ to $L$, we must be able to say

$$
\begin{aligned}
& x R a_{1} \\
& x R a_{2} \\
& x R a_{3}
\end{aligned}
$$

is true. 
it satisfies the criterion of identification $\left(C^{1}\right)$ and is not inconsistent with the hard core of minimum natural law $\left(C^{2}\right)$.

We can now consider the status of "dead letter" laws. Doubtless, there may be, as Professor Summers suggests, ${ }^{38}$ no point in a legal realist saying that a rule exists if it is persistently disregarded; there is, however, every reason for Professor Hart so to hold. Such a situation would arise because officials disregarded infractions or were unaware of them. Undoubtedly the rule will have lost its normativeness; and as a social rule, it could be said to have been abandoned. However, assuming that the legal system's criterion of identification is still accepted as such and that the rule is not inconsistent with minimum natural law, its social abandonment will not destroy its legal validity. Only the enactment of another valid rule of the system can cancel the validity of such a "dead letter" law. Part of the meaning of the expression "legal rule" in statements of the form "It is a legal rule that $p$ " is that the rule in question satisfies the dual criteria of validity; at the level of meaning there can be no exceptions. On the other hand, if the rule in question is one of the minimum natural law rules, its total disregard would mean for Professor Hart that the legal system had collapsed.

There remains the notion of justice which, for Professor Hart, is mainly a matter of how the rules are administered.90 All that justice requires us to say is that like cases be treated alike, while recognizing that the criteria for determining when, for any given purpose, cases are alike, will vary. This will apply to all legal rules, whether they are morally good or bad. Even an iniquitous law, says Professor Hart, will be justly administered if only persons genuinely guilty of breaking the law are punished under it and then only after a fair trial. However, such a law would have to pertain to the area of morality outside minimum natural law; for if it were inconsistent with minimum natural law, it could not be a valid legal rule in the first place. Presumably minimum natural law does not embrace the whole of morality.

I stated earlier that Professor Hart was doing analysis and therefore that his analysis of a legal system could not be expected to reveal

\footnotetext{
${ }^{80}$ Summers, supra note 1 , at 648 .

"HART 153-63; Hart, Introduction to Perelman, The IDEA of Justice AND the Problem of Argument (1963); Hart, Justice, 28 Philosophy 348 (1953).
} 
more than was contained in the analysandum. Insofar as the syntactical or formal meaning of validity is concerned, it is difficult to see any rational basis for differing with him, although we may, of course, disagree regarding those aspects of the semanatical meaning of law in relation to the world which are most deserving of attention. Because Professor Hart has chosen the relation of law and morals, it does not follow that he has excluded everything else. Let us hope, therefore, that he will see fit to enlighten us further. 